NASA Technical Memorandum 102651

\title{
Experimental Aeroelasticity History, Status and Future in Brief
}

\author{
Rodney H. Ricketts
}

(NASA-TM-102651) EXPERIMENTAL AFRTELASTICITY HISTORY, STATUS ANO FUTURE IN BRIFF (NASA) $14 \mathrm{P}$
CSCL 143
$N 90-21047$

Unclas

G3/09 0277020 
. 

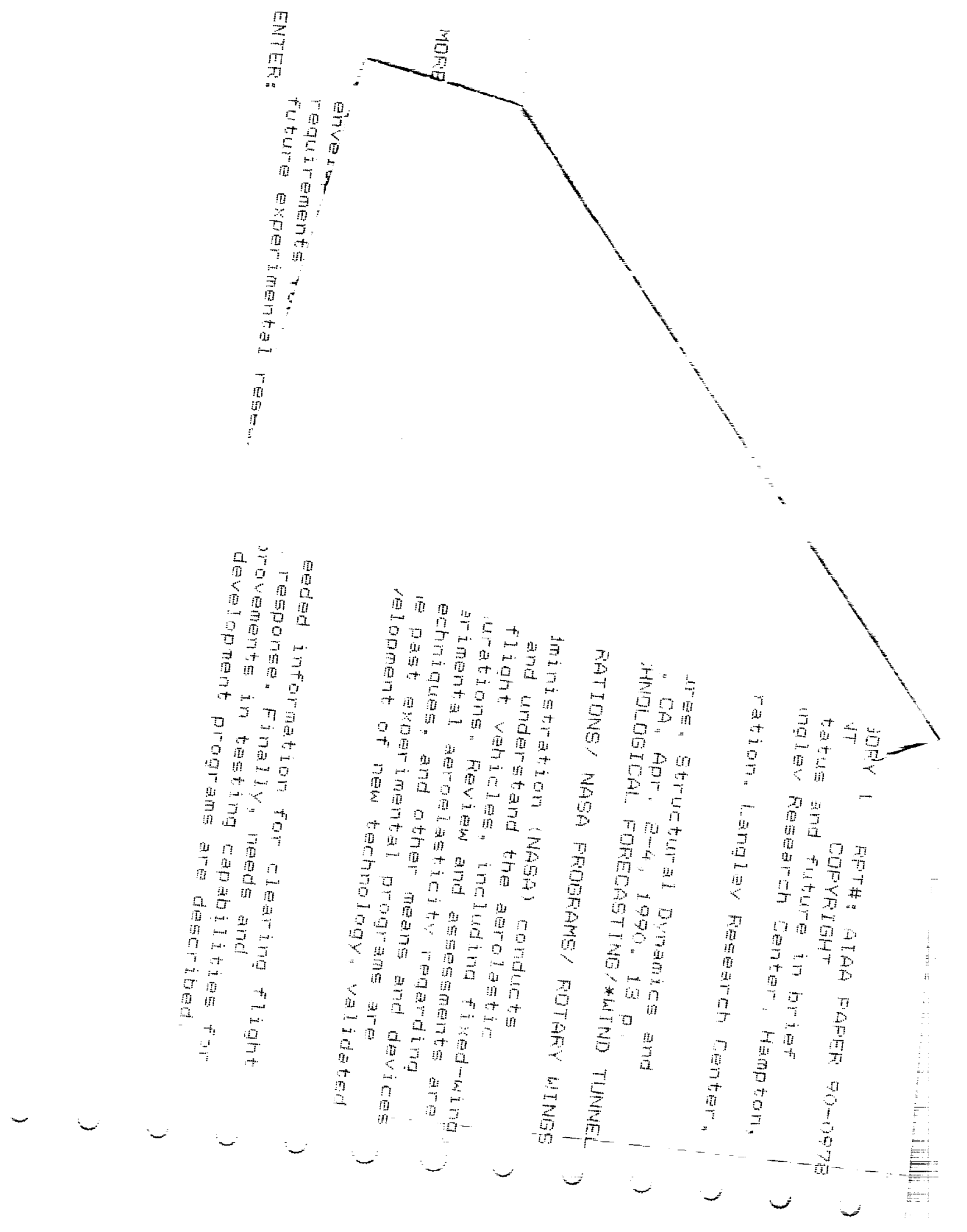


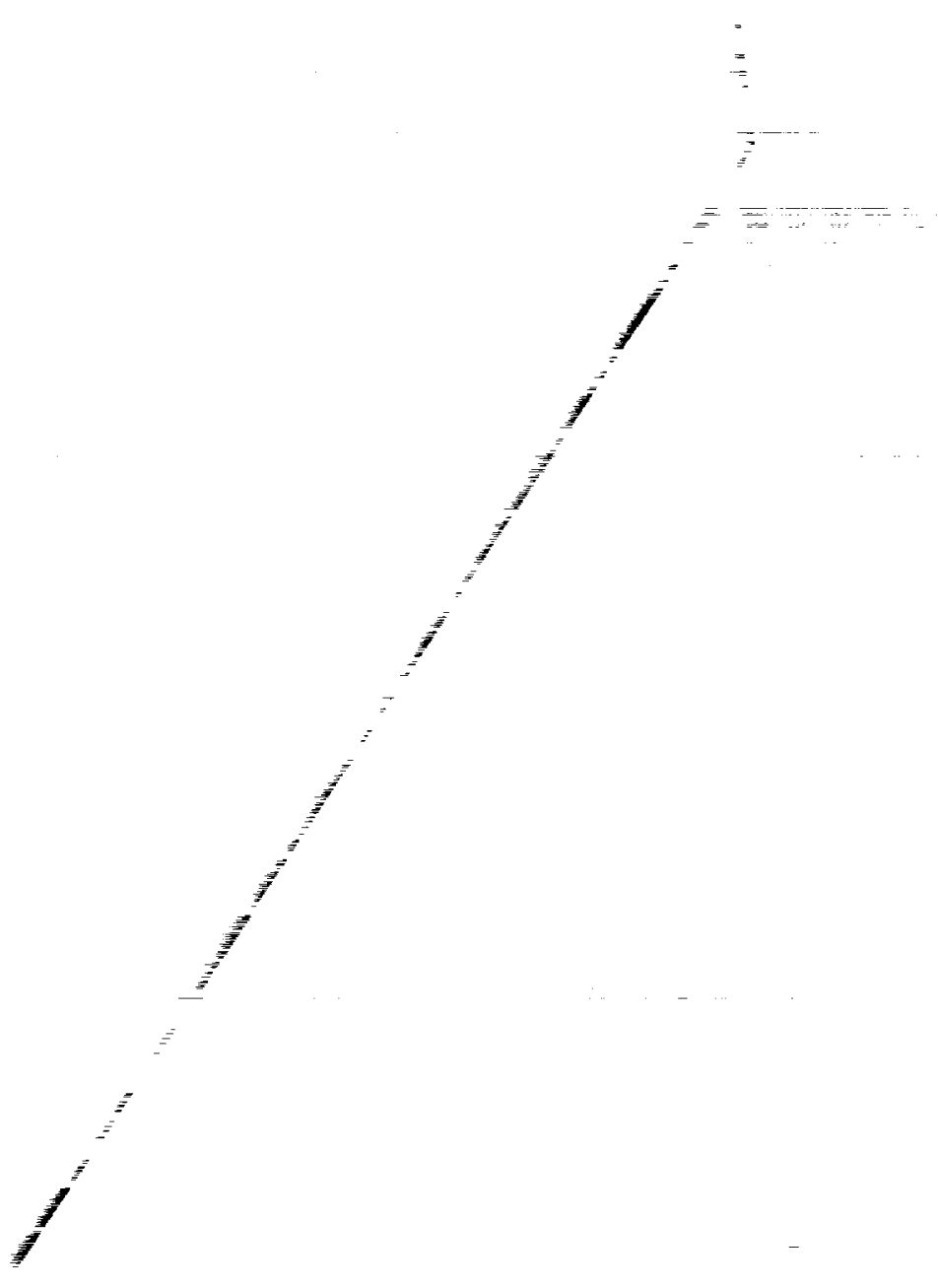

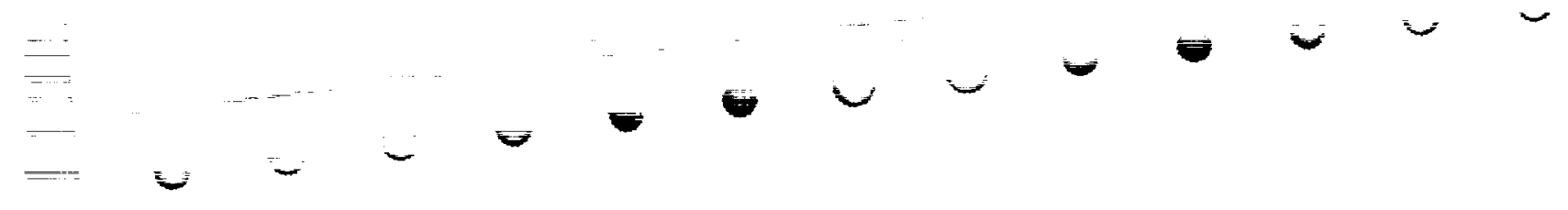




\title{
EXPERIMENTAL AEROELASTICITY -- HISTORY, STATUS AND FUTURE IN BRIEF
}

\author{
Rodney H. Ricketts* \\ NASA Langley Research Center \\ Hampton, VA 23665-5225
}

\section{ORIGINAL PAGEE \\ BLACK AND WHITE PHOTOGRAEH}

\begin{abstract}
The National Aeronautics and Space Administration (NASA) conducts wind-tunnel experiments to determine and understand the aeroelastic characteristics of new and advanced flight vehicles, including fixed-wing, rotary-wing and space-launch configurations. Review and assessments are made of the state-of-the-art in experimental aeroelasticity regarding available facilities, measurement techniques, and other means and devices useful in testing. In addition, some past experimental programs are described which assisted in the development of new technology, validated new analysis codes, or provided needed information for clearing flight envelopes of unwanted aeroelastic response. Finally, needs and requirements for advances and improvements in testing capabilities for future experimental research and development programs are described.
\end{abstract}

\section{Introduction}

It is well known that Orville and Wilbur Wright were the first to design and fly a heavier-than-air vehicle at Kitty Hawk, NC, in 1903. In the process of designing their Wright flyer, they became the first experimental aeroelasticians. They tested a model with a five-foot wing span to investigate their innovative wing-warp (twist) method for roll control in $1899^{1}$. A photograph and drawing of the model are shown in figure 1. In addition they experimented with propeller blades to determine that the tips at high thrust loadings were causing the blades to twist and washout the load2.

Since that time aeroelasticity has played a role in the design, testing or use of almost every new flight vehicle. Experiments in aeroelasticity have been conducted to validate analytical methods from the time (1935) of Theodorsen's development of flutter theory ${ }^{3}$ to present-day developments of computational aeroelasticity programs. Tests have been conducted to determine and understand the physics of aeroelastic phenomena such as flutter, divergence and buffet so that they could be taken into account during design efforts. Furthermore, experimental wind-tunnel testing has been performed on almost every aircraft, rotoncraft and space launch vehicle to demonstrate that the design is free of acroelastic problems before flight testing is begun.

\footnotetext{
* Head, Configuration Aeroelasticity Branch, Structural Dynamics Division, Member AIAA
}
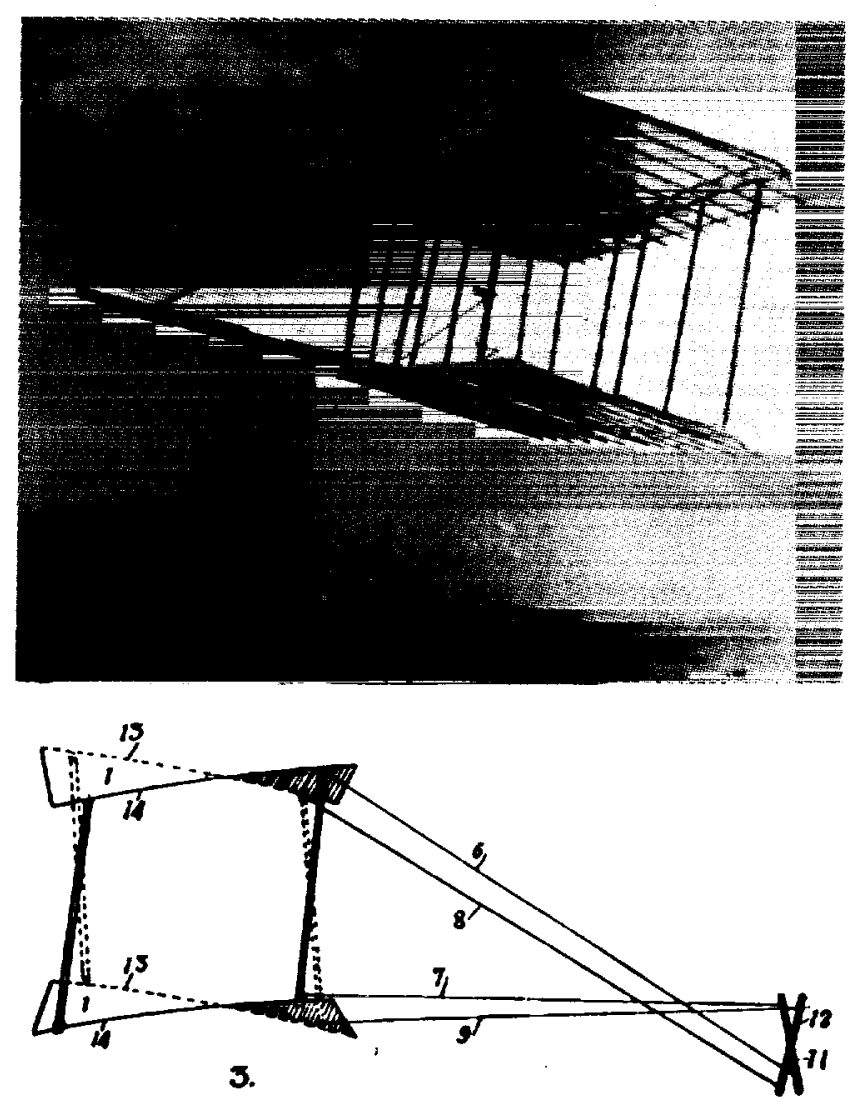

Figure 1. Wright Brothers' aeroelastic model.

This paper provides one assessment of the stateof-the-art of experimental aeroelasticity in the United States. A brief history of the development of ground test facilities, apparatus, and testing methods is presented. Several experimental programs are described that were previously conducted and helped to improve the state-ofthe-art. Finally, some specific future directions for improving and enhancing experimental aeroelasticity are suggested.

\section{Facilities}

In the early days of flight, some aeroelastic problems were solved using the method of trial and error. For example, when a flutter problem occurred on one 
1934 national air racer, the pilot systematically removed sections of the wing tip until the flutter problem was eliminated ${ }^{4}$. Because of the inherent danger involved in flutter testing, other methods were developed to solve aeroelastic problems. Structural laboratories and wind tunnels were constructed to enable these tests to be conducted more safely.

\section{Laboratories}

Static and dynamic structural test facilities are required to determine the elastic and dynamic characteristics of models prior to wind-tunnel testing. Almost all of these laboratories exist at government, industry and university installations and include the latest equipment available for conducting such experiments. Massive "back stops" and soft-spring systems are required to support properly the models during this testing. Stateof-the-art measurement equipment includes multi-point shaker systems, dynamic sensors, multi-channel data acquisition systems, and sophisticated modal analysis systems 5 .

\section{Wind Tunnels}

Aeroelastic models were tested initially in any available wind tunnel. This occurred because aeroelasticians did not have a facility which they could call their own. However, in 1945 a new four-and-one-half-foot diameter high subsonic tunnel ${ }^{6}$ became operational at NACA Langley Research Center and changed that situation. This tunnel was the first to be constructed for exclusive use in flutter research. The test section of this tunnel later was slotted to allow transonic testing. The portable test section in shown in figure 2. The tunnel used Freon as a test medium to enhance its capabilities. Although this tunnel is no longer in existence, other wind tunnels are available today for aeroelastic testing. These tunnels span the speed range from subsonic through hypersonic Mach numbers ${ }^{7-9}$.

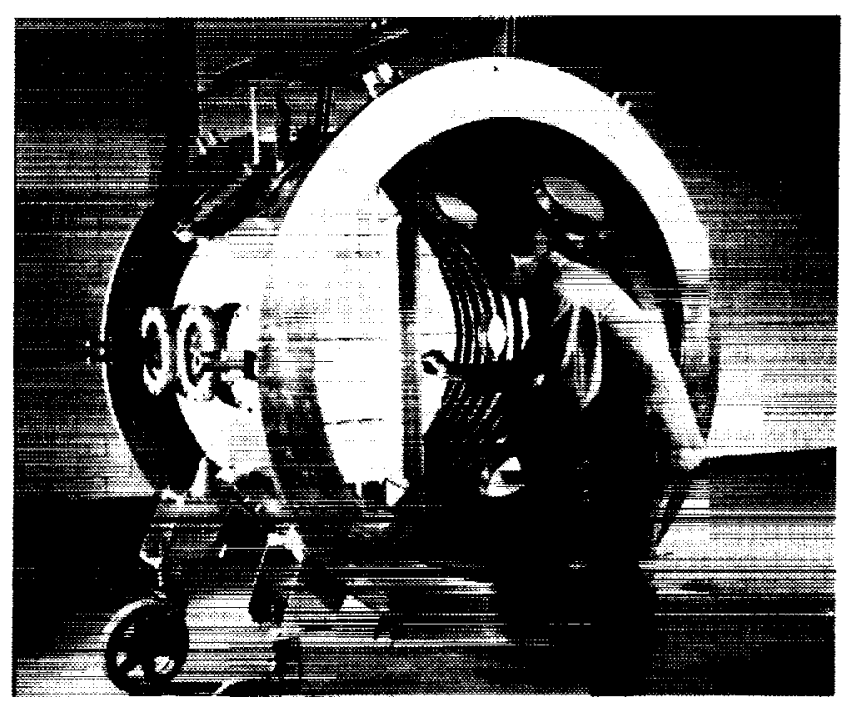

Figure 2. Portable test section of flutter tunnel (1945).
Subsonic wind tunnels which are available for aeroelastic testing include the following: government tunnels located at the Air Force Institute of Technology and David Taylor Naval Ship R\&D Center; industry facilities located at General Dynamics/Convair Division, Douglas/Long Beach, Northrop, and Rockwell; and, university tunnels located at the University of Washington, M.I.T. and Georgia Tech. A photograph of a model being tested in the Convair tunnel is shown in figure 3.

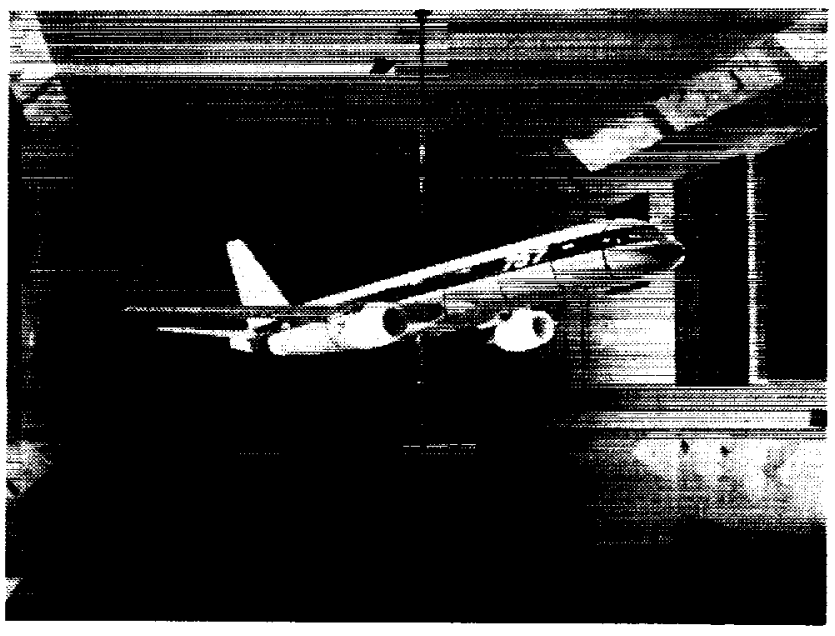

Figure 3. Flutter model in low-speed facility.

The transonic speed range has proven to be the most troublesome for aircraft aeroelasticity. In the 1950's the Langley 19-foot Pressure Tunnel was converted to the Transonic Dynamics Tunnel (TDT) ${ }^{10}$ specifically for support of aeroelastic research and development. A photograph of the TDT is shown in figure 4. Since the facility became operational in 1960, it has undergone several upgrades, including installation of airstream oscillators, development of data acquisition systems, and a 50 percent increase in test medium density capability. The combinations of large scale, high speed, high density, variable pressure, and a by-pass valve system make the TDT a unique facility for aeroelastic testing. For these reasons, the TDT is the primary tunnel used in the U.S. for aeroelastic testing of all classes of vehicles under development.

Other transonic facilities which are used for aeroelastic testing include the following: the 16-foot transonic tunnel (PWT-16T) at the USAF Arnold Engineering and Development Center (AEDC) and the NASA Ames 11-ft Transonic Tunnel where some studies 11,12 have been conducted. Also, some aeroelastic testing 13.14 has been conducted in the $0.3 \mathrm{~m}$ Transonic Cryogenic Tunnel (TCT) at NASA Langley. This tunnel was developed as the pilot tunnel for the National Transonic Facility (NTF) and uses high pressure and low temperature to give Reynolds number test capability on the order of flight values. 


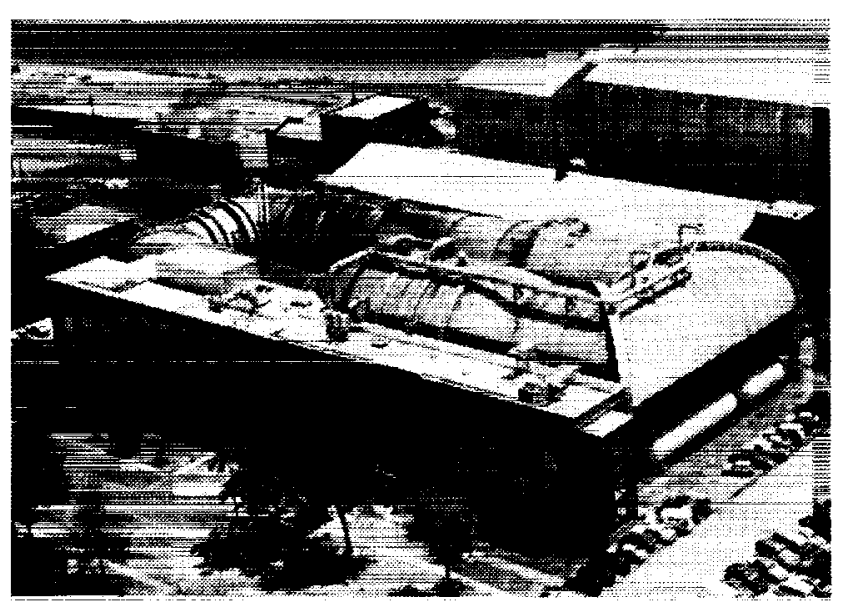

Figure 4. NASA Langley Transonic Dynamics Tunnel.

Considerable testing in the supersonic and hypersonic regimes was conducted in the 1950's and 1960 's, but not much testing has been done in recent years ${ }^{15}$. However, a few facilities still exist as NASA Langley for testing at these speeds. These include the Unitary Plan wind tunnels and the Hypersonic Helium Tunnel complex.

\section{Apparatus and Techniques}

Test apparatus and test methods have been developed and improved continuously through the years. Improvements have been made in the area of models and their mounting systems. New measurement devices and techniques have developed to better understand the aeroelastic phenomena. New methods and devices which are based on safety considerations have decreased the risk of model damage during testing.

\section{Models and Mounting Systems}

Several different methods are used in constructing aeroelastic models to maintain certain scaling parameters ${ }^{16}$. These methods range from relatively simple plate-like models covered with balsawood for basic research to complex replica models for validating fullscale-vehicle designs ${ }^{17}$. Examples of some of these construction techniques are shown in figure 5. Replica modeling was used extensively in the 1930's and 1940's. In this method, each spar and rib of a wing are scaled using the same material for the model as is used in the aircraft. However, this was an expensive method, and it became increasingly more difficult to model accurately more efficient structures. Therefore, a new method was developed which is known as "spar-and-pod" construction. In this method a single aluminum spar is used to represent the majority of the stiffness of a wing, for example, and uses segmented pods which are attached to it to provide the proper geometric shape and mass/inertia distributions (figure 5a). As vehicle aerodynamics and materials became more advanced (for example, supercritical airfoils and composites), improved modeling technology developed that allowed both smooth skins and anisotropic structures using layups of materials such as unidirectional fiberglass and graphite fibers over honeycomb or foam (figure $5 \mathrm{~b}$ ). Design and fabrication of complex full-span models of this type can cost as much as several million dollars. Today, any of these three construction techniques may be used in design and construction of wind-tunnel models. The simplest and least expensive technique that adequately represents the structural model and meets the test objectives is usually the method of choice.

Many sophisticated models are equipped with remotely actuated control devices. Electromechanical systems were used initially to drive control surfaces both statically and dynamically. Miniature hydraulic pumps and actuators were developed for use in active control applications $^{18}$. Today, completely self-contained hydraulic systems are feasible for use onboard models. These systems meet the high-power requirements and demonstrate adequate frequency response to near $50 \mathrm{~Hz}$. Currently, piezoceramic actuators are being used in some applications, including pitch control of rotorcraft blades and static warping of wing panels to control static aeroelastic response ${ }^{19}$.

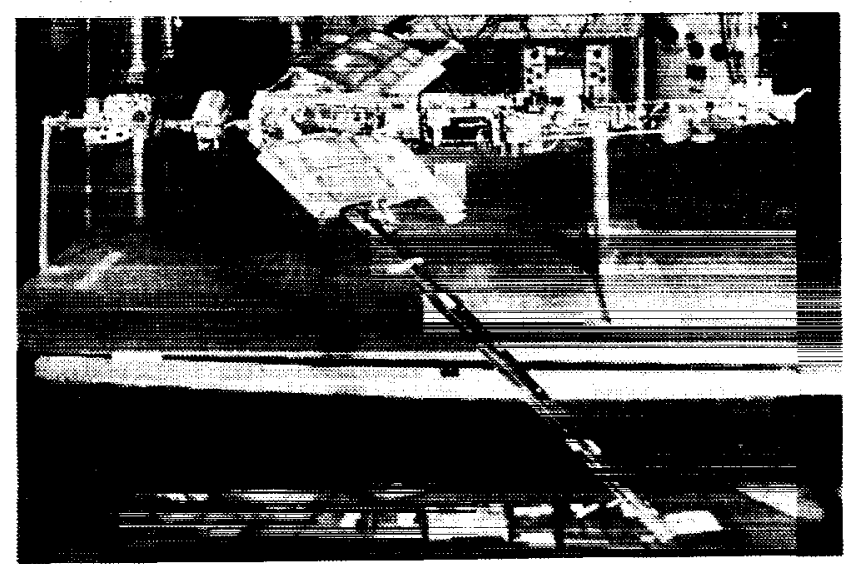

(a) Spar and pod construction.

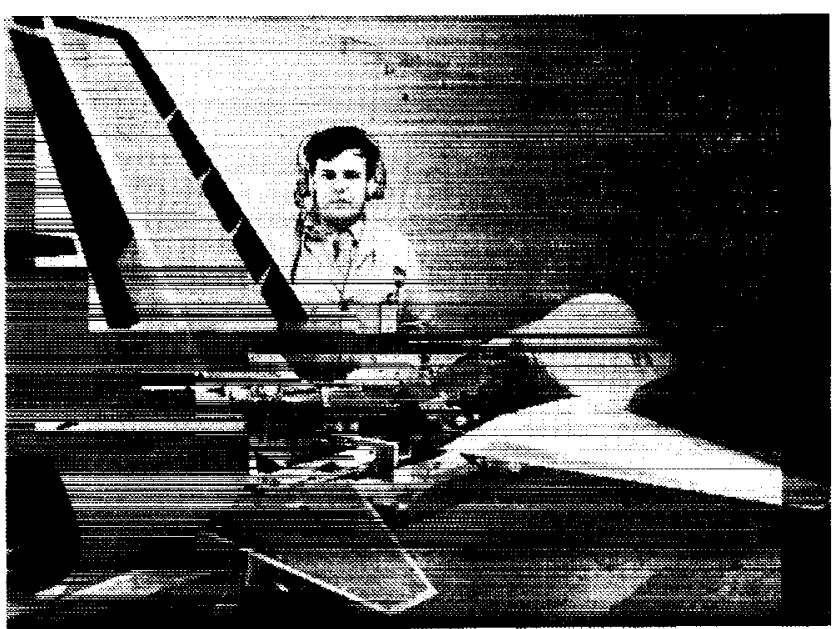

(b) Composite materials.

Figure 5. Model construction methods. 


\section{ORIGINAL PAGE \\ BLACK AND. WHITE PHOTOGRAPH}

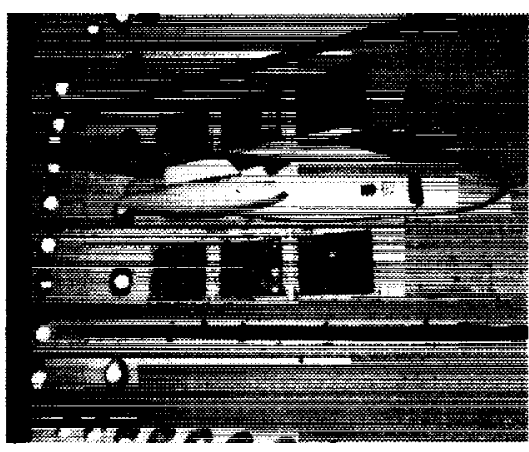

(a) Sidewall tumtable.

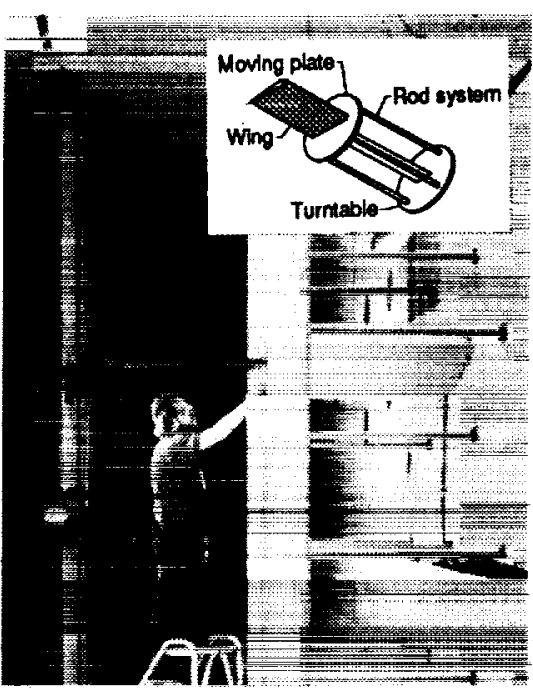

(d) Pitch and plunge apparatus.

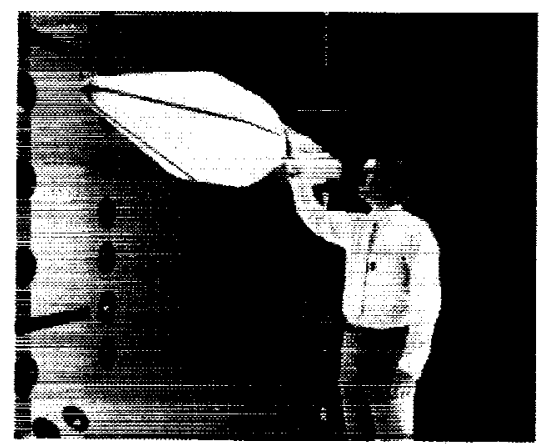

(b) Sting mount.

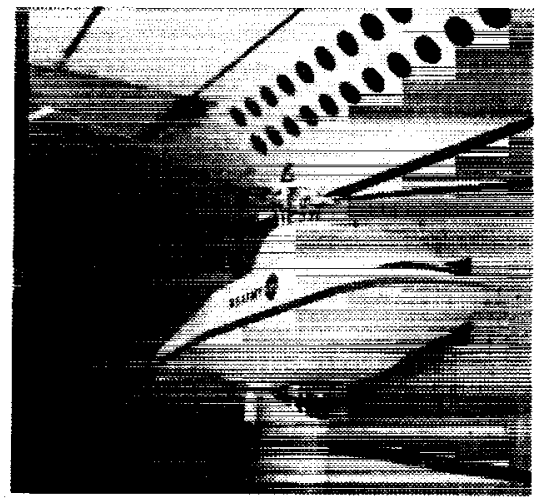

(e) Rotor testbed.

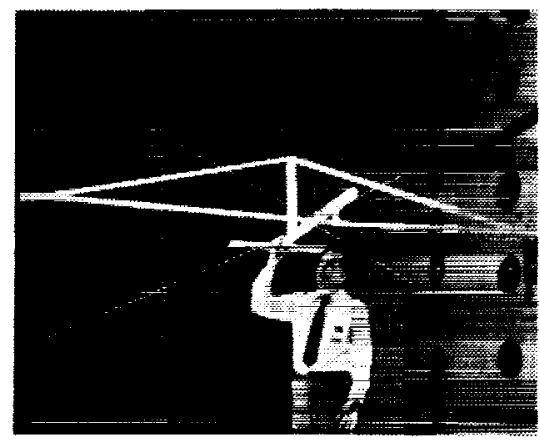

(c) 2-cable system.

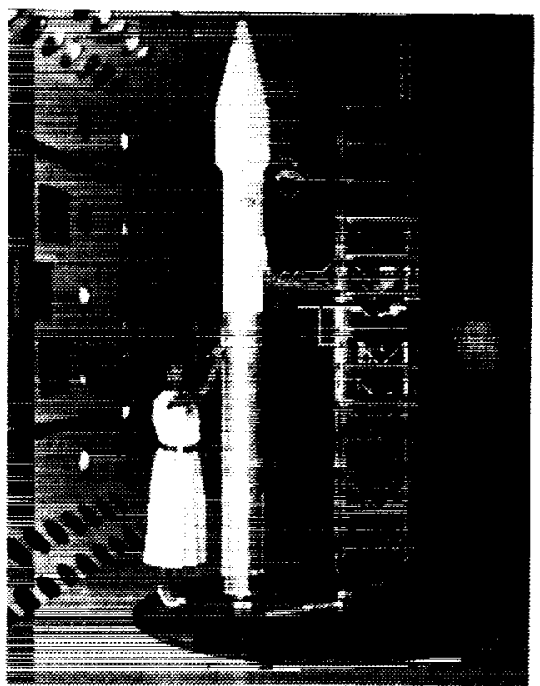

(f) Ground-wind loads turntable.

Figure 6. Model mounting systems.

During dynamic testing these same hydraulic systems are used to excite the model through the control surfaces. This provides a better means of excitation than does natural turbulence in the wind tunnel. Other excitation devices include oscillating vanes mounted at the wing tip 20 , rotating masses located in the fuselage, and oscillating jet streams exhausted from the wing tip.

Various means of mounting models in wind tunnels have been developed to accommodate the important degrees of freedom under study. Some of these are shown in figure 6. Semispan models can be mounted to the tunnel sidewall, ceiling or floor in cantilever fashion or on springs to simulate some rigid-body degrees of freedom and fuselage flexibilities (figure 6a). Full-span models can be mounted on a centerline sting, again using springs to simulate body freedoms (figure 6b). In highspeed tunnels, full-span models are mounted on a twocable system ${ }^{21}$ allowing movement in all degrees-offreedom except in the drag direction (figure $6 c$ ). A pitchand-plunge apparatus (PAPA) with well-known structural characteristics was developed 22 for flutter testing rigid wing models. The apparatus isolates the structural flexibilities from the unknown unsteady aerodynamic forces (figure 6d). Helicopter rotor systems are tested for aeroelastic performance and stability on rotor testbeds, for example the Aeroelastic Rotor Experimental System (ARES) $^{23}$ (figure 6e). Space launch systems are mounted on a floor turntable to allow rotation of the launch complex during ground-wind-loads tests (figure $6 \mathrm{f}$ ).

\section{Measurements}

Aeroelastic tests require static and dynamic measurements of both model response data and flow environment data. Instrumentation for acquiring these measurements usually must be lightweight relative to the model mass and nonintrusive so as not to alter the air flows. Strain gages, potentiometers, and accelerometers are commonly used for measuring structural loads, frequencies and damping levels. Gyros are used for measuring model displacements and rates. Manometers connected to orifices in models through long tubes were used initially to measure static pressure distributions. In 1952 small pressure transducers were developed ${ }^{24}$ for use in measuring fluctuating pressures on models. Since that 
time, the transducers have been further miniaturized and packaged, for example, as electronically scanned pressure (ESP) modules containing 50 sensors ${ }^{25}$, for use in measuring both steady and unsteady aerodynamic pressures. Thin surface-film gages have been developed for measuring the airfoil boundary-layer characteristics such as separation, transition and reattachment ${ }^{26}$.

Test engineers usually attempt to predict an aeroelastic instability condition before it occurs to reduce the risk of model damage. This is done by measuring subcritically the model responses and projecting the results to a neutral stability condition. Flutter prediction techniques in current use include randomdec, peakhold, and power spectral density (PSD) methods 27 . Techniques used for predicting static divergence of a forward-swept wing include a modified Southwell method and a Divergence Index method ${ }^{28}$. Transfer function methods are used to determine stability of models using active controls for flutter suppression ${ }^{29}$. A reliable technique used to predict the stability of helicopter rotors is the moving-block method $^{30}$. Experience has shown that no single prediction method is reliable for all situations. Therefore, several methods might be used during an aeroelastic test.

Proper characterization of the flow is necessary to understand fully the physics of an aeroelastic phenomenon. In the 1950's, schlieren methods aided in understanding the shock movement associated with aileron buzz. Laser velocimetry methods are used to understand vortex flows over wings at high angles of attack ${ }^{31,32}$. Recently, a laser system was developed which uses propylene glycol particles to see the patterns in dynamic flows. It can be strobbed at specified frequencies and uses photography, video, and movie film to record the flow ${ }^{33}$. A schematic of this system and a photograph showing vortex flow results on a clipped-delta wing are shown in figure 7.

The requirements for computer data acquisition systems has increased through the years. Recording time histories for large numbers of pressure transducers has raised the requirements for computer memory, disk storage, data sampling rates, and number of signal conditioners and amplifiers. Examples of such systems are given in references 34 and 35 . In addition, small portable signal analyzers and minicomputers are used to acquire and process data for subcritical response techniques, for example, fast Fourier transform and recursive identification methods.

Safety

Model safety is very important in aeroelastic testing because of the high risk of damage to both the model and wind-tunnel facility. Several devices have been developed to reduce this risk. For instance, doors are opened into the flow to divert the airstream and to block the flow to the model, or quick-acting by-pass valves "short circuit" the flow between the high-pressure test section and the low pressure leg to reduce rapidly the

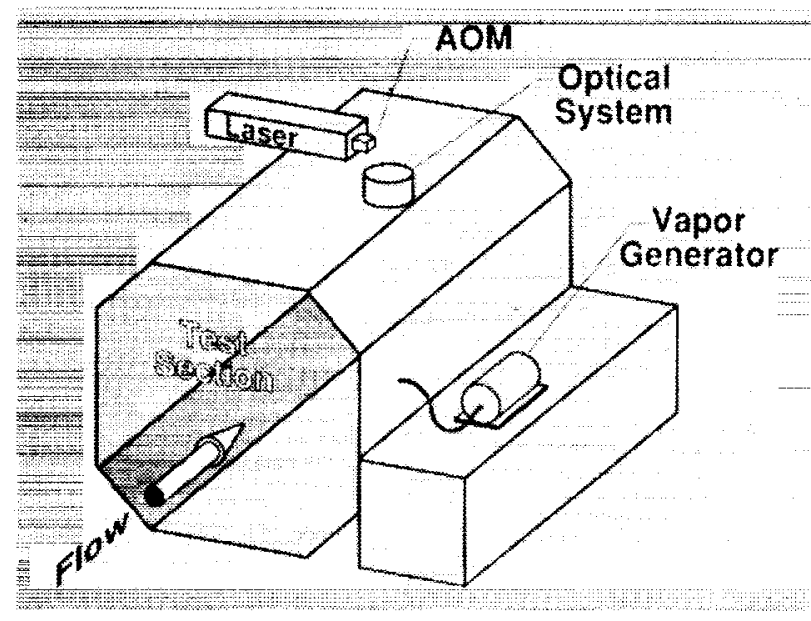

(a) Installation in wind tunnel.

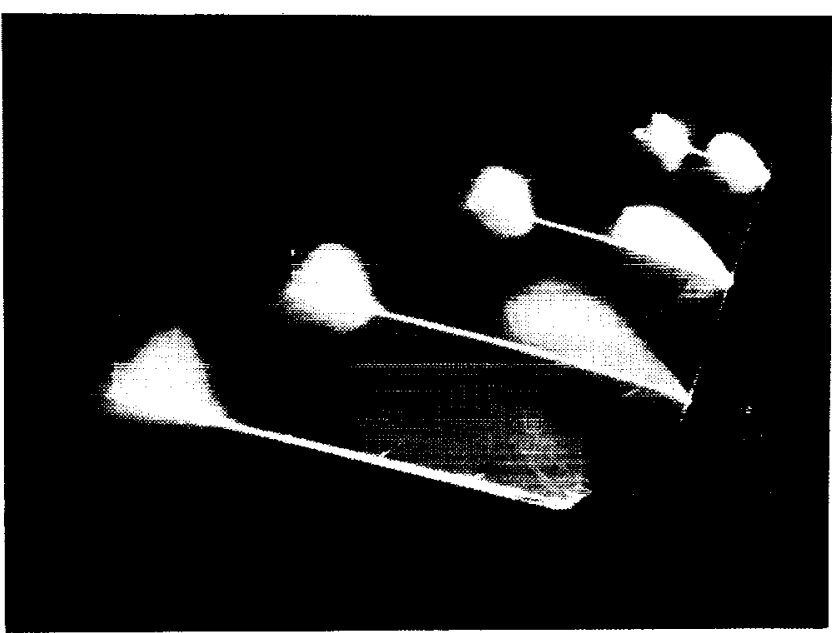

(b) Vortex flow on model wing.

Figure 7. Laser light sheet flow visualization system.

dynamic pressure at the model. Additional cables, called "snubbers", are routinely attached to full-span models on the two-cable-mount system to be tightened quickly to add stiffness and damping to an unstable model. These cables can be seen in figure $6 \mathrm{c}$ located near the model center of gravity and oriented at $45^{\circ}$ angles to the vertical centerline. Another constraining device rolls stiff arms from the wing root toward the tip over both top and bottom surfaces to restrict wing motion 28 . The "constrainer" deployed on a forward-swept-wing model is shown in figure 8a. Wall-mounted shields have also been developed to divert flow away from the model in time of need. Some safety devices, such as spoilers, are installed on the models and deployed to disnupt the aerodynamic flow and uncouple it from the instability mode ${ }^{36}$. Other model-installed devices can change the stiffness or mass properties of the model to prevent damage during testing. For example, one model incorporates a "decoupler" boom attached to the model wing tip using a pivot support with 


\section{ORIGINAL PAGE \\ BLACK AND. WHITE PHOTOGRAYH}

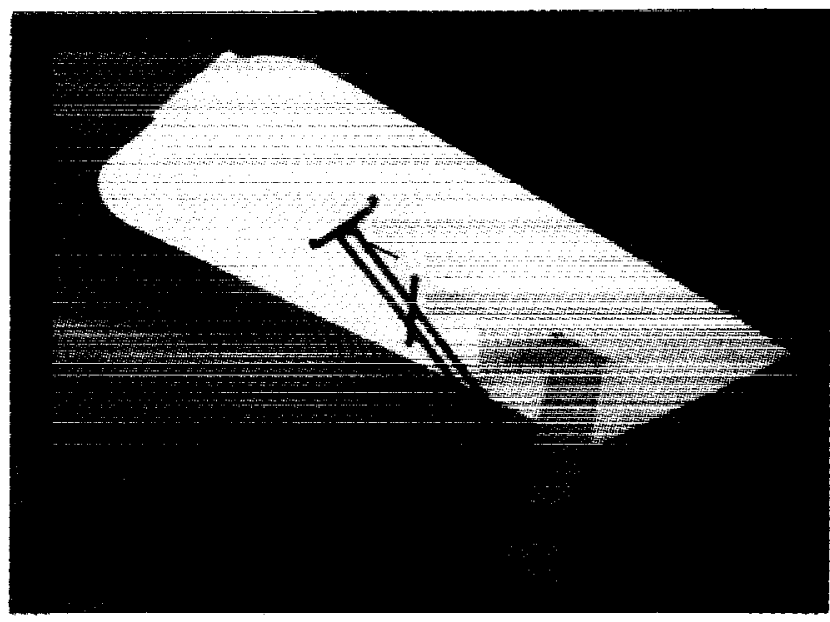

(a) Constrainer arms.
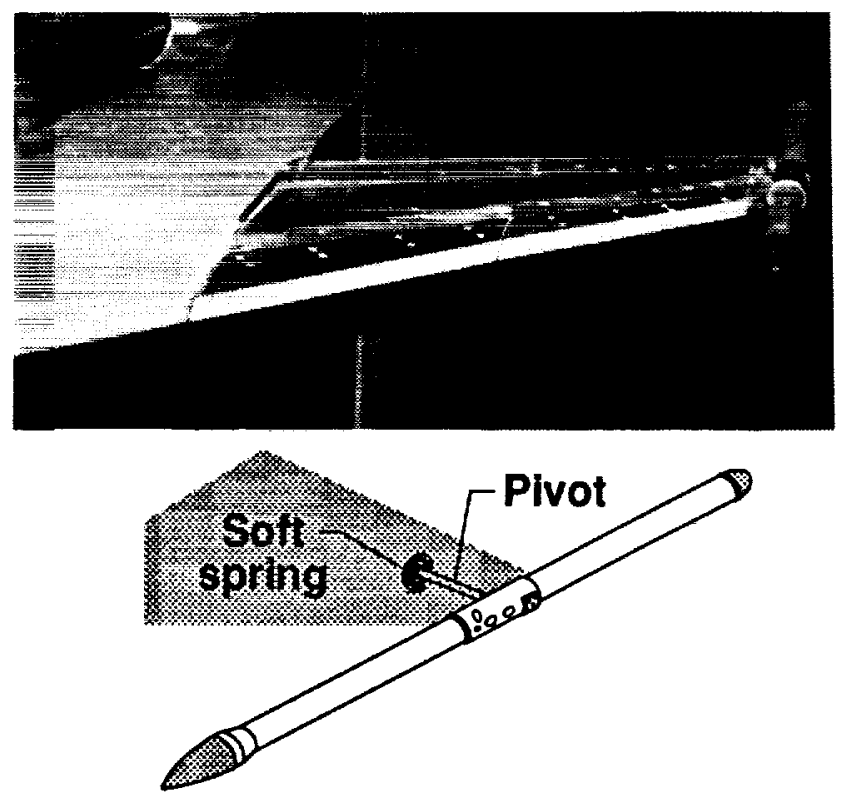

(b) Decoupler pod.

Figure 8. Safety devices for increasing model stability.

two separate pitch stiffnesses. This is illustrated in figure 8 b. The model was tested normally with a primary pitch stiffness condition (stiff). If flutter occurred, the model was quickly switched to a secondary stiffness condition (softer) to raise the model stability boundary ${ }^{37}$. This is an adaptation of the decoupler-pylon concept developed to control flutter of wings with stores in a passive manner ${ }^{38}$. Also, electronic circuits have been developed to monitor model response and activate the previously described safety devices when set dynamic levels have been exceeded.

\section{Experimental Programs}

Many experimental programs in aeroelasticity have been conducted through the years. Extensive studies in subsonic wing-aileron flutter, transonic aileron buzz, and supersonic panel flutter have been undertaken to understand and find solutions to the problems. Experimental programs have also been conducted to validate vehicle designs, to develop new technology, and to validate new analytical codes. Examples of clearance tests and experimental programs in structures, aerodynamics and controls are discussed here. Most of these tests were conducted in the Langley TDT.

\section{Envelope Clearance Tests}

Flight testing is the final authority in defining aeroelastic characteristics of flight vehicles. However, most flight programs are preceded by wind-tunnel tests to demonstrate that new vehicle designs are free from all unwanted static and dynamic response or instabilities throughout the simulated flight envelope. In cases where the model is aeroelastically deficient, either the design is modified or the envelope is placarded. Tests in low-speed tunnels are often conducted to determine effects of many parameter variations, such as stiffnesses and locations of engine pylons of transport wings. The Langley TDT has been used for almost every major U. S. aircraft development program and for some rotorcraft and space vehicle development programs 39-41. Comparisons between flight measurements and TDT wind-tunnel results have been good for a variety of tests ${ }^{42}$. These comparisons have validated the model simulation methods and test techniques used in the tests.

The F-16 airplane is a good example of this type program. It originally was developed as an air-to-air fighter but later was used to carry a large variety of other stores. Tests in the TDT supported by analysis were conducted to determine critical store loading and to eliminate the need for flight testing many others. A photograph of the F-16 with a variety of stores that were flutter tested during one entry in the TDT is shown in figure 9. The F-16 was then flight flutter tested throughout its envelope to confirm the results of windtunnel tests and analysis.

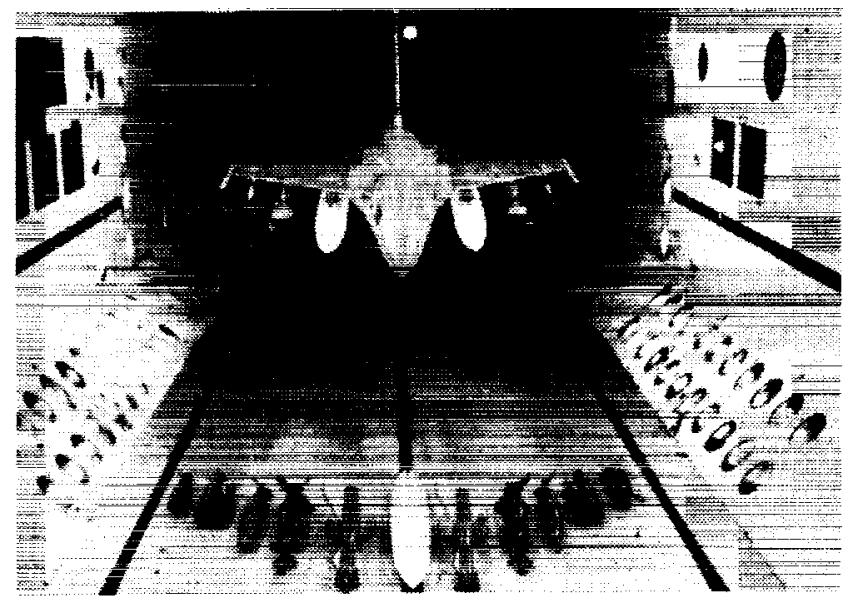

Figure 9. F-16 flutter clearance model with stores. 


\section{ORIGINAL PAGE BLACK AND WHITE EHOTOGRAPH}

\section{Aeroelastic Tailoring}

With the development of composite materials technology came innovative applications to structures and aeroelasticity. Many wind-tunnel experiments have been conducted to determine the performance and stability of aeroelastic tailored wings and to verify analysis capabilities $^{43}$. Tests of forward swept-wing models were conducted in the TDT to determine the static divergence characteristics of the tailored designs. Static aeroelastic tests of three fighter-type wings were conducted at AEDC to evaluate the effects of washin and washout in comparison with results with an untailored design. Flutter tests in the TDT were also conducted on similar wings with the same washin and washout designs 44 . These wings are shown in figure 10 . In addition, wing static divergence and body-freedom flutter phenomena of tailored forward-swept-wing designs were investigated in tests at AFWAL and in the TDT ${ }^{45-48}$.

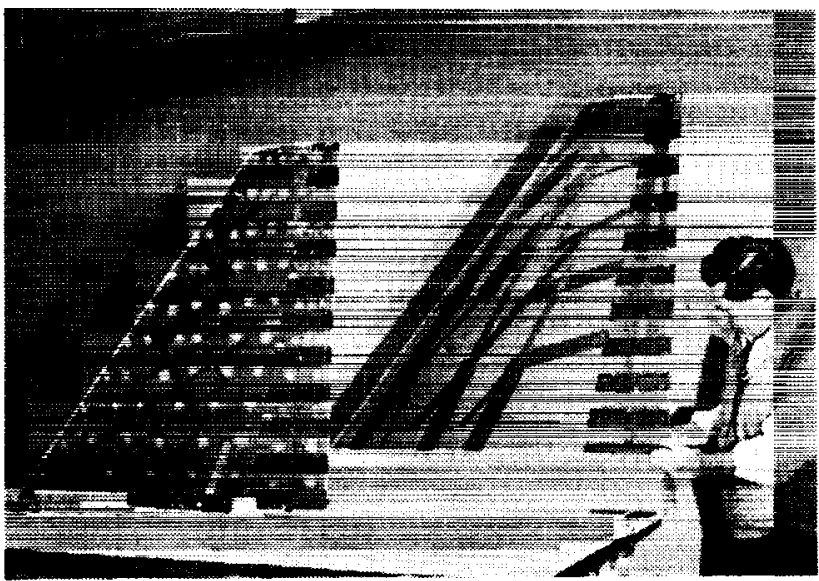

Figure 10. Washout and washin tailored wings.

\section{Unsteady Aerodynamics}

To better understand the unsteady aerodynamics of oscillating wings and controls and to validate new transonic aerodynamic codes, an experimental program was conducted on a variety of wind-tunnel models. Some of the models are shown in figure 11. The models were highly instrumented with pressure transducers and tested to acquire a large database of information. Pseudo rigid models include a clipped-delta wing (figure 11a) and a rectangular supercritical wing (figure 11b) which were oscillated in pitch and a high-aspect-ratio wing (figure 11c) with multiple oscillating control surfaces. A cantilevered flexible transport wing was also included. These three models were tested in the $\mathrm{TDT}^{49}$. In addition, testing was conducted on a two-dimensional wing model (figure 11d) in the $0.3 \mathrm{~m}$ TCT to determine the effects of Reynolds number on unsteady aerodynamics ${ }^{14}$.

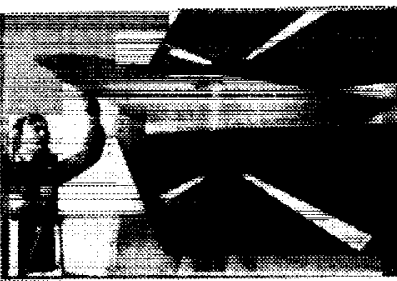

(a) Delta wing.

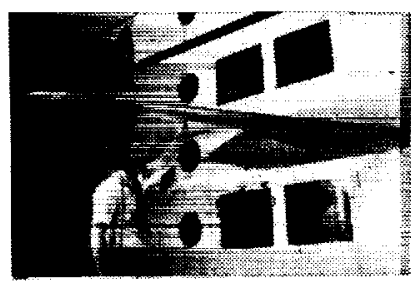

(c) High-aspect-ratio wing.

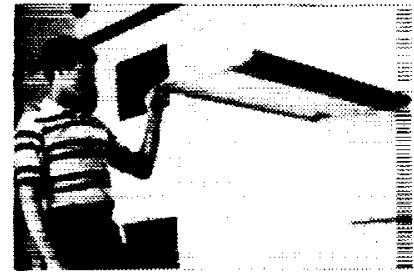

(b) Supercritical wing.

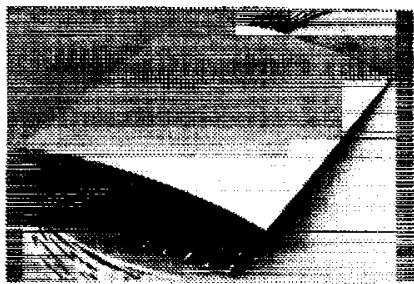

(d) 2-D airfoil.
Figure 11. Unsteady pressure models.

\section{Active Controls}

Development of active controls technology for improvement of aeroelastic response has relied heavily on experimental demonstrations and validations. Experiments in active controls have been conducted to suppress wing and store flutter, to improve aircraft static stability, to increase wing roll control and to reduce aircraft gust response and helicopter rotor blade dynamic response 50,51 . The first wind-tunnel demonstration was conducted in 1972 on a clipped-delta wing model ${ }^{18}$ with a leading-edge and a trailing-edge control for suppressing flutter. Flutter and gust response were suppressed in tests of a DC-10 model. Digital and adaptive systems were developed on a YF-17 model with stores. In these examples, the controllers were single function. The current trend in active controls is to develop multifunction systems, or systems which can control a variety of responses at the same time. The Active Flexible Wing (AFW) model was tested to develop a system that can simultaneously suppress flutter and achieve desired roll response by controlling leading and trailing-edge surfaces. Photographs of these four active control models are shown in Figure 12.

\section{Future Directions}

While an assessment of experimental aeroelasticity indicates that the technology is mature, not everything to be known about aeroelastic behavior is known. System behavior caused by structural nonlinearities (such as joint damping or freeplay), transonic aerodynamic phenomena (such as shocks, flow separations, and viscosity), and active control system performance are still difficult or impossible to predict. Furthermore, the physics of some aerodynamic/structures interactions are not fully understood. Two examples are the limit cycle oscillations (LCO) experienced on F-16 type wings with certain store configurations and the 


\section{BLACK AND WHITE PHOTOGRAPH}

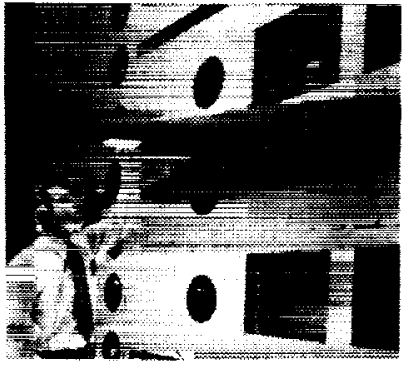

(a) Clipped-delta wing.

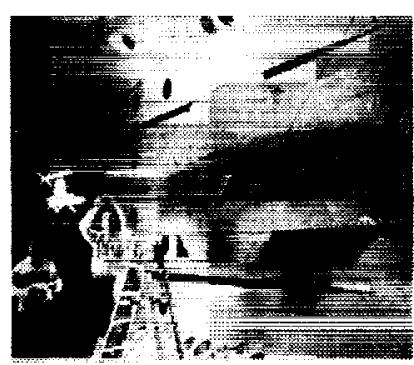

(c) YF-17 wing.

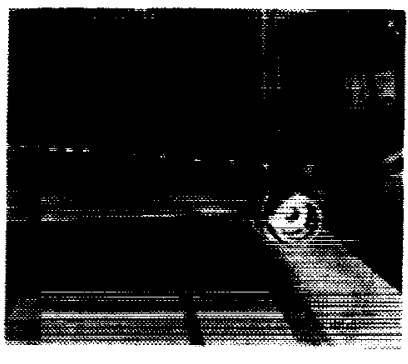

(b) DC-10 wing.

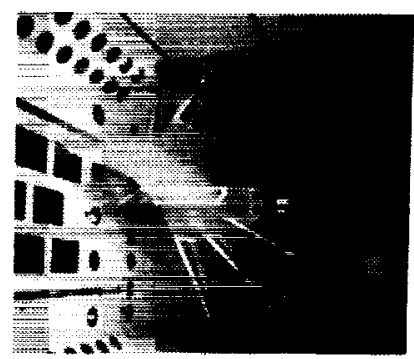

(d) AFW model.
Figure 12. Active control models.

shock-induced flow separation instability experienced on the ARW-2 supercritical wing configuration 52 . Therefore, experiments will continue to be necessary for validation of new analytical codes and for understanding new aeroelastic phenomena. Continued enhancement of facilities, development of additional special equipment/techniques, and the conduct of new studies will be necessary.

\section{Eacilities}

The TDT will remain dedicated to aeroelastic testing. NASA continues to invest heavily in the facility as evidenced by the Major Construction of Facilities $(\mathrm{CoF})$ project to upgrade the Freon reclamation system by the end of 1991. In the future, it would be advantageous to extend the transonic Mach number capability to 1.4. This would allow a better definition of phenomena in the low supersonic region where analytical codes have difficulty in predicting accurate results. Because the use of heavy gas is a viable means for acquiring data high at Reynolds number, Boeing is planning the construction of a new wind-tunnel complex which uses $\mathrm{SF}_{6}$. Although a final decision has not been made to initiate the project, studies indicate that a large tunnel for aeroelastic testing will be part of the project.

The National Transonic Facility at NASA Langley has high Reynolds number capability. It is desirable to use this facility to study aeroelastic phenomena which are sensitive to Reynolds number effects, such as the impact of boundary layer separations and shock interactions on unsteady aerodynamics ${ }^{53}$.

\section{Apparatus and Techniques}

Additional developments in equipment and techniques are needed to enhance aeroelastic test capabilities. A few examples are mentioned here. Advanced rotorcraft testbeds which allow six rigid-body degrees of freedom are needed to study rotor/airframe coupling. The ARES testbed is being upgraded with active controlled hydraulic actuators to provide this capability 54 . A new aircraft model mounting system which employees the ARES-type active control concepts to allow rigid body degrees of freedom could be useful for testing certain configurations. Advantages over cable and rod systems may include decreased risk of model loss and elimination of disturbances in the flow upstream of the model. A new testbed is also needed to study experimentally the aeroelastic characteristics of advanced high-speed rotorcraft designs using tilt and folding rotors, including aeroelastically tailored forward-swept wings and rotors. In addition, nonintrusive dynamic systems for measuring the flow fields and response of models in the wind tunnel are needed to characterize the unsteady airloads and structural modes during testing. Work is currently underway to develop global velocimetry methods, such as the global particle imaging approach 55 for measuring unsteady flow fields. Similarly a system is needed for measurement of both static and dynamic model deformations. Furthermore, subcritical response techniques are needed to predict the onset of LCO-type phenomena by measuring the stability of the flow boundary layer and shock movement.

\section{Programs}

Future experimental programs in aeroelasticity will be conducted to provide data for code validation, to understand better the basic physics, and to develop new technologies required for advanced vehicles. One such program has been initiated by NASA Langley for aeroelastic code validation. Models are being designed to study conventional flutter, non-classical flutter (for example, LCO), and vortex-flow effects on flutter and buffet $^{54}$. These models include "rigid" wings on the PAPA support system and flexible models on sidewall mounts. The models will be instrumented extensively to measure insitu pressures and model displacements. A laser light-sheet flow visualization system will be used to study the off-surface flow conditions. Furthermore, validation of new codes which couple aeroelasticity with other disciplines is needed. A new program to integrate all of the technical disciplines at Langley (including structures, aerodynamics and controls) for aircraft was initiated this past year. The focus of this program is high speed civil transports (HSCT). Because previous designs of supersonic transports have had critical flutter problems, transonic tests will be conducted to determine flutter behavior sensitivities with regard to aeroelastic tailoring, aerodynamics and active control system variables for use in code validation. Some results which have been obtained to support this effort are shown in figure 13. In this study the flutter characteristics of three models with 


\section{ORIGINAL PAGE \\ BLACK AND WHITE PHOTOGRAPH}
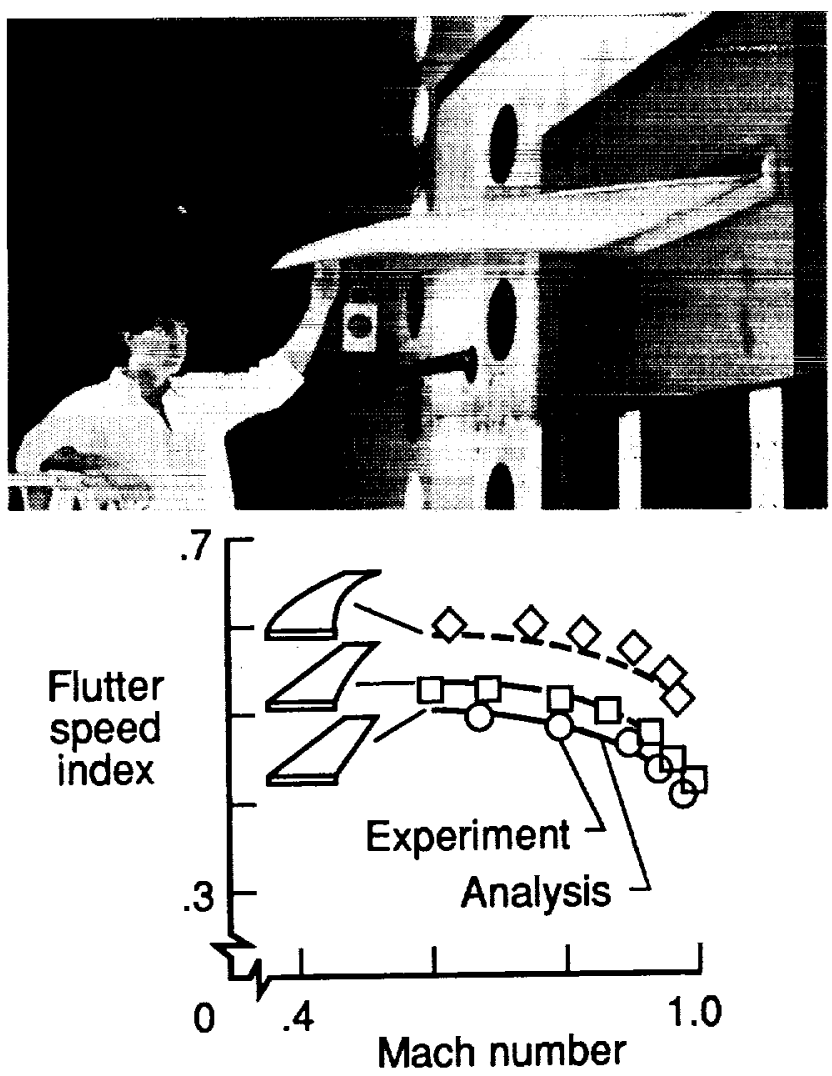

Figure 13. Curved planform flutter model results.

different planform curvature were measured. Many other parameters, such as engines, wing fins, and fuel loadings, have been measured on an arrow wing design ${ }^{56}$. A program for optimization of rotorcraft is also underway 57 . This work includes the integration of aerodynamics, structures, and structural dynamics. Results of one experiment to determine the vibration sensitivities to the location of a non-structural mass are shown in figure 14. Finally, a new thrust in high-speed rotorcraft will require technology developments in aeroelasticity. Vertical takeoff/landing and 0.7 Mach number cruise capability may lead to designs using folding or stowed rotors on forwardswept wings. Integrated aeroelastic tailoring and active controls technology may be needed to meet the challenges in rotor dynamics and aeroelasticity.

\section{Concluding Remarks}

The state-of-the-art in experimental aeroelasticity has been reviewed with respect to available facilities, models, special techniques and test equipment. The aeroelasticity discipline has progressed in an evolutionary manner throughout this century (since 1899). Adequate facilities are now available for testing throughout the simulated flight regime, especially at transonic speeds. The Langley TDT was emphasized and will continue to receive support in maintaining its status as a unique facility dedicated solely to research and development in aeroelasticity. Model construction methods have kept pace with the technology developments that are being modeled. Many special techniques and testing equipment have been developed to support aeroelastic experiments However, new testbeds for studying advancements in rotorcraft and new systems which measures dynamic flow fields and model displacements without interference are needed.

Some past experimental programs have been described which assisted in the development of new technology, validated new analysis codes, or provided needed information for clearing flight envelopes of unwanted aeroelastic response. These included the development of aeroelastic tailoring, active control technology and the measurement of an extensive unsteady aerodynamics database. Future programs are needed to gather additional aerodynamic data to validate aeroelastic codes and to validate integrated methodology for both high-speed aircraft and rotorcraft. Three programs addressing these needs are currently underway at NASA Langley. Furthermore, integration of many disciplines will be needed to develop an advanced high-speed rotorcraft.

It is still true today what was spoken by I. E. Garrick in his 1976 Von Karmon Lecture ${ }^{58}$. "The
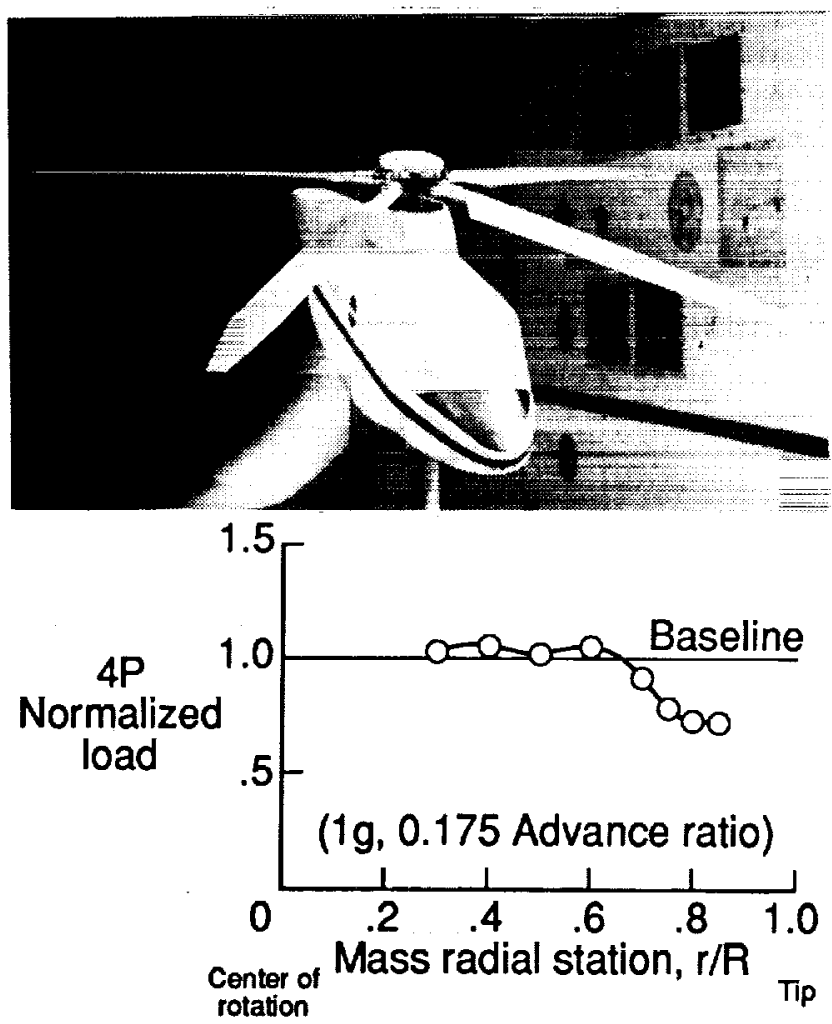

Figure 14. Rotor dynamic sensitivities to added mass. 
aeroelastician must develop insight into the physics of a problem so that the wide use of computers and black boxes can be a real blessing rather than a reliance on black magic". With this charge and with the challenges still before us, the need for quality experiments in aeroelasticity will continue for quite some time into the future. It is doubtful that one will ever be able to rely solely on the computer for development of advanced aerospace vehicles.

\section{References}

1 Gibbs-Smith, Charles H.: The Wright Brothers, A Brief Account of Their Work 1899-1911. Science Museum, 1987.

2 Garrick, I. E.; and Reed, W. H., III: Historical Development of Aircraft Flutter. AIAA Journal of Aircraft, Vol. 18, No. 11, November 1981.

3 Theordsen, T.: General Theory of Aerodynamic Instability and the Mechanism of Flutter. NACA Report 496, 1935.

4 Tolve, L.: History of Flight Flutter Testing. Proceedings of the 1958 Flight Flutter Testing Symposium. New Printing, NASA SP-385, 1975.

5 Langley Aerospace Test Highlights--1988. NASA TM 101579, 1989.

6 Hansen, James R.: Engineer in Charge. NASA SP4305, 1987.

7 Pope, Alan; and, Harper, John J.: Low-Speed Wind Tunnel Testing. John Wilcy \& Sons, Inc., 1966.

8 Pope, Alan; and, Groin, Kennith L.: High-Speed Wind Tunnel Testing. Robert E. Krieger Publishing Company, 1978.

9 Penaranda, Frank E.: Aeronautical Facilities Assessment. NASA RP-1146, 1985.

10 Baals, Donald D.; and Corliss, William R: Wind Tunnels of NASA. NASA SP-440, 1981.

11 Braymen, W. W.; Rogers, W. A.; and, Shirk, M. H.: Wind-Tunnel Test and Aerodynamic Analysis of Three Aeroelastically Tailored Wings. Proceedings of the 13 th Congress of the Intemational Council of the Aeronautical Sciences (ICAS). Seattle, Washington, 1982.

12 Dobbs, S. K.; and, Miller, G. D.: Self Induced Oscillation Wind Tunnel Test of a Variable Sweep Wing. Presented at AIAA/ASME/ASCE/AHS 26th Structures, Structural Dynamics and Materials Conference, Orlando, Florida. AIAA Paper No. 85$0739,1985$.
13 Cole, Stanley R.: Exploratory Flutter Test in a Cryogenic Wind Tunnel. NASA TM-86380, 1985.

14 Hess, R. W.; Seidel, D. A.; Igoe, W. B.; and Lawing, P. L.: Transonic Unsteady Pressure Measurements on a Supercritical Airfoil at High Reynolds Numbers. AIAA Joumal of Aircraft, Vol. 26. No. 7, July 1989.

15 Reed, Wilmer H., III; Hanson, Perry W; and, Alford, W. J., Jr: Assessment of Flutter Model Testing Related to the National Aero-Space Plane. NASP CR-1002, 1987.

16 Regier, Arthur A.: The Use of Scaled Dynamic Models in Several Aerospace Vehicle Studies. Proceedings of ASME Colloquium on Use of Models and Scaling in Shock and Vibration, Philadelphia, Pennsylvania. 1963.

17 Cooley, Dale E.; and Cook, Robert F.: Dynamic Modeling, Its Past and Future. Proceedings of Symposium on Aeroelastic \& Dynamic Modeling Technology, Dayton, Ohio. USAF Report No. RTD-TDR-63-4197, 1964.

18 Sandford, Maynard C.; Abel, Irving; and Gray, David L.: Development and Demonstration of a FlutterSuppression System Using Active Controls. NASA TR R-450, 1975.

19 Crawley, E.F.; and Lazarus, K. B.: Induced Strain Actuation of Isotropic and Anisotropic Plates. Proceedings of AIAA/ASME/ASCE/AHS/ASC 30th Structures, Structural Dynamics and Materials Conference, Mobile, Alabama. Paper No. 89-1326CP, 1989.

20 Reed, Wilmer H., III: Selected Topics in Aircraft Flutter Testing Technology. Presented at the First South African Aeronautical Engineering Conference, Pretoria, South Africa, May 25-27, 1988.

21 Reed, W. H., III; and Abbott, F. T., Jr: A New FreeFlight Mount System for High-Speed Wind-Tunnel Flutter Models. Proceedings of Symposium on Aeroelastic \& Dynamic Modeling Technology, Dayton, Ohio. USAF Report No. RTD-TDR-63$4197,1964$.

22 Farmer, Moses G.: A Two-Degree-of-Freedom Mount System with Low Damping for Testing Rigid Wings at Different Angles of Attack. NASA TM $83302,1982$.

23 Mantay, Wayne R., et. al.: Aeroelastic Model Helicopter Rotor Testing in the Langley TDT. Presented at the AHS Specialists' Meeting on Helicopter Test Methodology, Williamsburg, Virginia, 1984. 
24 Patterson, John L.: A miniature Electrical Pressure Gage Utilizing a Stretched Flat Diaphragm. NACA TN 2659, 1952.

25 Malon, Joseph R.: A Fifty Channel Electrically Scanned Pressure Module. Proceedings of the 23rd International Instrumentation Symposium, Las Vegas, Nevada, 1977.

26 Stack, J. P.; Mangalam, S. M.; and, Berry, S. A.: A Unique Measurement Technique to Study Laminar Separation Bubble Characteristics on an Airfoil. Proceedings of AIAA 19th Fluid Dynamics, Plasma Dynamics and Lasers Conference, Honolulu, Hawaii, 1987. Paper No. 87-1271.

27 Ruhlin, Charles L.: Evaluation of Four Subcritical Response Methods for On-Line Prediction of Flutter Onset in Wind-Tunnel Tests. AIAA Journal of Aircraft, Vol. 20, No. 10, October 1983.

28 Ricketts, Rodney H.; and Doggett, Robert V., Jr.: Wind-Tunnel Experiments of Divergence of ForwardSwept Wings. NASA TP-1685, 1980.

29 Houbolt, John C.: On Identifying Frequencies and Damping in Subcritical Flutter Testing. Proccedings of the Conference on Flutter Testing Techniques, Dryden Flight Research Center, Edwards, California, 1975. NASA SP-415.

30 Hammond, Charles E.; and, Doggett, Robert V., Jr.: Determination of Subcritical Damping by MovingBlock/Randomdec Applications. Proceedings of the Conference on Flutter Testing Techniques, Dryden Flight Research Center, Edwards, California, 1975. NASA SP-415.

31 Settles, Gary S.: Modern Developments in Flow Visualization. AIAA Journal, Vol. 24, No. 8, August 1986.

32 Scllers, William L.; and, Kjelgaard, Scott O: The Basic Aerodynamics Research Tunnel--A Facility Dedicated to Code Validation. Proccedings of AIAA 15th Aerodynamic Testing Conference, San Diego, Califomia, 1988. Paper No. 88-1997.

33 Gardner, James E.: Struciural Dynamics Division Research and Technology Accomplishments for FY 1988 and Plans for FY 1989. NASA TM 101543, 1989.

34 Cole, Patricia H.: Wind Tunnel Real-Time Data Acquisition System. NASA TM 80081, 1979.

35 Turkovic, Robert J.: Computers Monitor Aircraft Wind (-Tunnel) Testing. Automation, July 1988, pp 76-77.

36 Cole, Stanley R.: Effects of Spoiler Surfaces on the Aeroelastic Behavior of a Low-Aspect-Ratio
Rectangular Wing. Proceedings of AIAA/ASME/ASCE/AHS/ASC 31 th Structures, Structural Dynamics and Materials Conference, Long Beach, California. Paper no. 90-0981-CP, 1990.

37 Noll, T.; and, et.al.: Aeroservoelastic Wind Tunnel Investigations Using the Active Flexible Wing Model--Status and Recent Accomplishments. Proceedings of AIAA/ASME/ASCE/AHS/ASC 30th Structures, Structural Dynamics and Matcrials Conference, Mobile, Alabama. Paper No. 89-1168CP, 1989.

38 Reed, W. H., III; Foughner, J. T., Jr.; and Runyan, H. L., Jr.: Decoupler Pylon: A Simple, Effective Wing/Siore Flutter Suppressor. AIAA Joumal of Aircraft, Vol. 17, No. 3, March 1980.

39 Reed, Wilmer H., III: Aeroelasticity Matters: Some Reflections on Two Decades of Testing in the NASA Langley Transonic Dynamics Tunnel. Presented at the International Symposium on Aeroelasticity. Nuremberg, Germany, 1981. (Also available as NASA TM-83210, 1981.)

40 Ricketts, Rodney H.: Selected Topics in Experimental Aeroelasticity at the NASA Langley Research Center. Proceedings of the Second International Symposium on Aeroelasticity and Structural Dynamics, Aachen, Germany. Paper No. 85-21, 1985. (Also available as NASA TM 86436, 1985.)

41 Doggett, Robert. V., Jr; and Cazier, F. W., Jr.: Aircraft Aeroelasticity and Structural Dynamics Research at the NASA Langley Research Center-. Some Illustrative Results. Proceedings of 16th Congress of the International Council of the Aeronautical Sciences (ICAS), Jerusalem, Israel, 1988.

42 Reed, Wilmer H., III: Comparisons of Flight Measurements with Predictions from Aeroelastic Models in the NASA Langley Transonic Dynamics Tunnel. AGARD Conference Proceedings No. 187 on Flight/Ground Testing Facilities Correlation. Valloirc, Savoie, France, 1975.

43 Shirk, Michacl H..; Hertz, Terrence J.; and Weisshaar, Terrence A.: A Survey of Aeroelastic Tailoring Theory, Practice, Promise. Proceedings of AIAA/ASME/ASCE/AHS 25th Structures, Structural Dynamics and Materials Conference, Palm Springs, California. Paper No. 84-0982-CP, 1984.

44 Murphy, A. C.; Rogers, W. A.; Shirk, M. H.; and Ruhlin, C. L.: The Design, Testing and Analysis of Aeroelastically Tailored Transonic Flutter Model Wings. Proccedings of AIAA/ASME/ASCE/AHS 24th Structures, Structural Dynamics and Materials Conference, Lake Tahoe, Nevada. Paper No. 83 1027-CP, 1983. 
45 Blair, Maxwell: Wind Tunnel Experiments on the Divergence of Swept Wings with Composite Structures. AFWAL-TR-82-3018, 1982.

46 Hertz, T. J.; Shirk, M. H.; Ricketts, R. H.; and, Weisshaar, T. A.: On the Track of Practical ForwardSwept Wings. Astronautic \& Aeronautics, January 1982.

47 Chipman, R.; Rauch, F.; Rimer, M.; Muniz, B; and Ricketts, R.: Transonic Test of a Forward Swept Wing Configuration Exhibiting Body Freedom Flutter. Proccedings of AIAA/ASME/ASCE/AHS 26th Structures, Structural Dynamics and Materials Conference, Orlando, Florida. Paper No. 85-0688CP, 1985.

48 Harris, T. M.; Noll, T. E.; Hertz T. J.; and Sotomayer, W. A.: A review of Aeroelastic Research at the Flight Dynames Laboratory. Procecdings of the Second International Symposium on Acroclasticity and Structural Dynamics, Aachen, Germany. DGLR-Bericht 85-02, 1985.

49 Sandford, M. C.; Ricketts, R. H.; and Hess, R. W.: Recent Transonic Unsteady Pressure Measurements at the NASA Langley Research Center. Proccedings of the Second International Symposium on Aeroclasticity and Structural Dynamics, Aachen, Germany. DGLR-Bericht 85-02, $1985 . \quad$ (Also available as NASA TM 86408, 1985.)

50 Hanson, Perry W.: An Aeroelastician's Perspective of Wind Tunnel and Flight Experiences with Active Control of Structural Response and Stability. NASA TM 85761, 1984.

51 Abcl, I.; and, Noll, T. E.: Research and Applications in Aeroservoelasticity at the NASA Langley Research Center. Proceedings of $16 \mathrm{th}$ Congress of the International Council of the Acronautical Scicnces (ICAS). Jerusalem, Israel, 1988.

52 Eckstrom, C. V.; Seidel, D. A.; and, Sandford, M. C.: Unsteady Pressure and Structural Response Measurements on an Elastic Supercritical Wing. Proceedings of AIAA/ASME/ASCE/AHS 29th Structures, Structural Dynamics and Matcrials Conference, Williamsburg, Virginia. Paper No. 882277-CP, 1988.

53 Hanson, Perry W.: An Assessment of the Future Roles of the National Transonic Facility and the Langley Transonic Dynamics Tunnel in Aeroelastic and Unsteady Aerodynamic Testing. NASA TM $81839,1980$.

54 Smith, Jacqueline G.; and Gardner, James E.: Structural Dynamics Division Research and Technology Accomplishments for FY 1989 and Plans for FY 1990. NASA TM 101683, 1990.
55 Smith, C. A.; Lourenco, L. M. M.; and, Krothapalli, A.: Measuring Flow with Laser-Speckle Velocimetry. NASA Tech Briefs, Vol. 12, No. 9, October 1988.

56 Durham, Michael, H.; and, et. al.: Experimental Transonic Flutter Characteristics of Supersonic Cruise Configurations. Proceedings of AIAA/ASME/ASCE/AHS/ASC 31 th Structures, Structural Dynamics and Materials Conference, Long Beach, California. Paper No. 90-0979-CP, 1990.

57 Adelman, Howard M.; and Mantay, Wayne R.: An Initiative in Multidisciplinary Optimization of Rotorcraft. NASA TM 101523 and AVSCOM TM 88-B-016, 1988.

58 Garrick, I. E.: Aeroelasticity-Frontiers and Beyond. AAIA Journal of Aircraft, Vol. 13, No. 9, September 1976. 


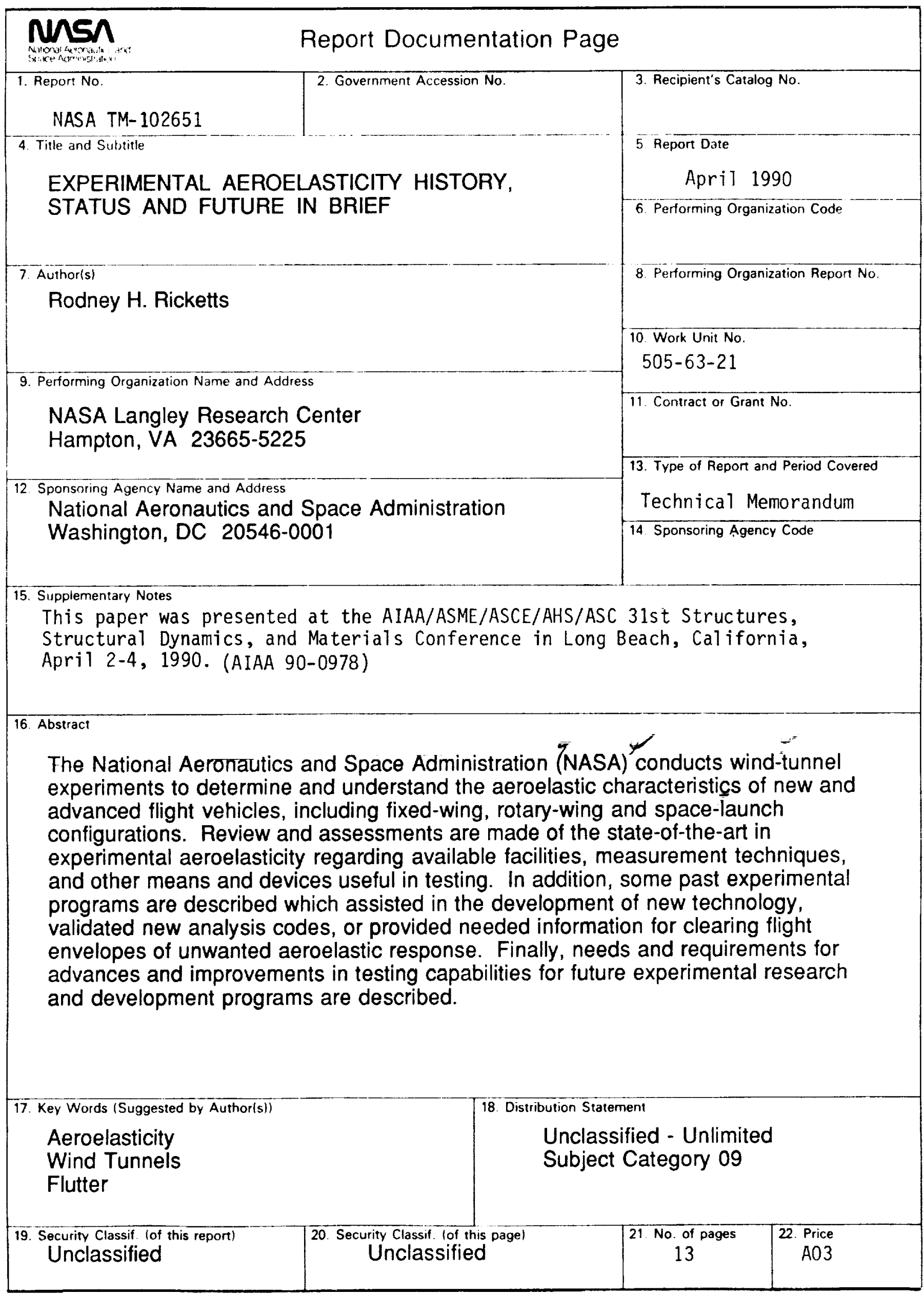


